\title{
Characterisation and identification of local kaolin clay from Ghana: A potential material for electroporcelain insulator fabrication
}

\author{
Abu Yaya ${ }^{1}$, Elvis K. Tiburu ${ }^{2}$, Mary E. Vickers ${ }^{3}$, \\ Johnson K. Efavi ${ }^{1}$, Boateng Onwona-Agyeman ${ }^{1}$, Kevin M. Knowles* ${ }^{3}$ \\ 1 Department of Materials Science and Engineering, School of Engineering Sciences, \\ College of Basic and Applied Sciences, University of Ghana, Legon. \\ 2 Department of Biomedical Engineering, School of Engineering Sciences, College of \\ Basic and Applied Sciences, University of Ghana, Legon. \\ 3 University of Cambridge, Department of Materials Science and Metallurgy, 27 \\ Charles Babbage Road, Cambridge CB3 OFS, UK. \\ *Corresponding Author: kmk10@cam.ac.uk
}

\begin{abstract}
The aim of this work was to evaluate two kaolin clays from the southern part of Ghana, Assin-Fosu and Kumasi clays, as source clays for the fabrication of electroporcelain insulators. X-ray diffraction, differential thermal analysis, thermogravimetric analysis, chemical analyses and scanning electron microscopy observations showed the fired clay minerals have broadly similar characteristics, but with significant differences in their chemical composition. The alumina contents were determined to be $35 \pm 2 \mathrm{wt} \%$ and $22 \pm 2$ wt $\%$ respectively for the two kaolins and the silica contents $49 \pm 3 \mathrm{wt} \%$ and $58 \pm 3 \mathrm{wt} \%$ respectively. It is concluded that Assin-Fosu kaolin is a reliable local source material for electroporcelain fabrication, while Kumasi kaolin is more suitable for making wall and floor tiles.
\end{abstract}

Keywords: Assin-Fosu kaolin, Electroporcelain insulators, Kaolin, Kumasi kaolin, X-ray diffraction. 


\section{Introduction}

Clay products have been used worldwide for processing various forms of ceramic materials since antiquity (Velde, 1992; Murray, 2000; Bertolino and Lagaly, 2003). Clay is still used today in the ceramics industry for producing products such as whitewares, high temperature porcelains, sanitary ware and electrical insulators (Carty and Senapati, 1998). The major mineral constituent of the clay used for porcelain is kaolinite; rocks rich in this mineral are typically referred to as either 'china clay' or 'kaolin'. Kaolinite is one of the mineral phases used widely in the clay industry for making many products, including paper (Brindley and Nakahira, 1959; Stathis et al., 2004; Olupot et al., 2010). In addition, kaolin has also found extensive usage in the pharmaceutical, paint and composite materials industries (Murray et al., 1993). The choice of china clay or kaolin for industrial applications is dependent on several factors including specific requirements for developing a particular technology (Nkoumbou et al., 2009). These requirements are dependent on the geological conditions under which the kaolin deposits originate, as well as their mineralogical and chemical composition and degree of kaolinite crystallinity, and physical properties such as colour and firing characteristics (Cases et al., 1986; Cravero et al., 1997; Ekosse, 2000; Pinheiro et al., 2005; Siddiqui et al., 2005; López-Galindo et al., 2007).

The clay industry in Africa, and in Ghana in particular, dates back several centuries because the material is ubiquitous. Natives of the continent find, or have found historically, use for clay for both domestic and industrial applications. The production of pottery and red bricks, geophagy, sculpture, rituals, and plastering are just some of the ways in which kaolin are used in Ghana (Goody, 1972). Most of the recent scientific studies conducted in Ghana on kaolin deposits have focused on understanding the use of kaolin as a reinforcement in composites and as a source material for the production of refractory bricks and porous filters (Efavi et al., 2012; Yaya et al., 2012; Dodoo-Arhin et al., 2013; Agyei-Tuffour et al., 2014). In contrast to this, the potential usefulness of these kaolin deposits for the production of electroporcelain insulators relevant to the continued development of the national electricity transmission network within Ghana has not been considered.

Electroporcelain insulators are materials of choice for both low and high tension insulation (Iqbal and Lee, 1999). These are complex multi-component ceramic materials made from clays, fluxes and fillers. These three ingredients react together under thermal conditions to produce the final product (Carty and Senapati, 1998). Despite significant research already conducted in this field, challenges still remain in understanding the 
properties relating to the selection and investigation of raw materials, their processing, microstructure and phase evolution, all which are critical determinants for their use as electric insulation materials (Cravero et al., 1997; Iqbal and Lee, 1999; Choudhary and Patri, 2009).

One obvious variable in the production of electroporcelain insulators is the source or sources of the clay, because critical aspects of a particular clay, such as its elemental composition, its phase constitution, its microstructure and its plasticity are all a function of geological conditions. These characteristics of a clay are instrumental in determining whether it can be used in the fabrication of electrical insulators.

It is evident that there is significant potential for the use of local clay materials, as well as fluxes and fillers such as feldspar and quartz, to manufacture electroporcelain insulators in Ghana, since all of these materials are readily available in mineral deposits within the country. The objective of the work reported here was to evaluate the properties of two clays taken from two different locations in Ghana in order to establish their suitability for the fabrication of electroporcelain insulators.

\section{Materials and methodology}

\subsection{Sources of the raw materials}

The raw kaolin materials for this study were collected from the Assin-Fosu and Kumasi kaolin deposits in Ghana located in the Central region and the Ashanti region respectively (Fig. 1).

\subsection{Powder preparation and analysis}

In preparing powders used in this study, $400 \mathrm{~g}$ quantities of the lumpy kaolin deposits, one from the Kumasi deposits and one from the Assin-Fosu deposits, were first ground using a Thomas grinding machine to break up the agglomerates. The samples were each further milled for $11 \mathrm{~h}$ in a cascading ball mill using alumina balls to reduce the particle size and obtain fine powders.

After milling, the particle size distribution of each of the two powders was analysed using a five-stack sieve set arranged in the sequence of International Organization for Standardization (ISO) nominal aperture sizes of $630 \mu \mathrm{m}, 500 \mu \mathrm{m}, 355 \mu \mathrm{m}, 90 \mu \mathrm{m}$ and $63 \mu \mathrm{m}$ from top to bottom to determine how well the two sources of clay had milled. Particle sizes below $90 \mu \mathrm{m}$ were used from the two sets of sieved powders for the characterisation studies. 


\subsection{Chemical composition testing}

Chemical analysis of the kaolin powders was obtained using a Spectro XLab 2000 XRay Fluorescence (XRF) spectrometer (AMETEK USA), located at the Ghana Geological Survey. $4 \mathrm{~g}$ of each sample sieved through the $90 \mu \mathrm{m}$ sieve was mixed with $1 \mathrm{~g}$ of Licowax powder which served as a binder. The mixture was milled for $5 \mathrm{~min}$ in a Retsch milling machine (model MM 301) and pressed in an XRF pellet press. The powder samples were then loaded into the Spectro XLab 2000 sample holders for the XRF analysis.

\subsection{Loss on ignition}

This measurement was carried out on raw powdered samples of the two kaolins fired in an electric kiln at a temperature of $1000^{\circ} \mathrm{C}$ for $2 \mathrm{~h}$.

\subsection{XRD experiments and degree of order and disorder}

X-ray powder diffraction patterns of the kaolinite samples were obtained using a Philips PW1820 ( $\theta / 2 \theta)$ automatic powder diffractometer equipped with a graphite secondary monochromator, operating at $40 \mathrm{kV}$ and $40 \mathrm{~mA}$ with $\mathrm{CuK}_{\alpha}$ radiation and a step size of $0.05^{\circ}$ $2 \theta\left(2^{\circ}-45^{\circ}\right)$ at a counting time of $4 \mathrm{~s}$ per step. The diffraction patterns were matched against records in the International Centre for Diffraction Data (ICDD) database using the book by Brindley and Brown (1980) as a source reference for the identification of clay minerals, and analysed using the X'pert HighScore Plus software (Panalytical, Netherlands). Estimates of the relative fractions of different phases in the two kaolinite samples in wt $\%$ were achieved by Rietveld analysis using calculated X-ray diffraction patterns from the Inorganic Crystal Structure Database (ICSD).

\subsection{Scanning electron microscopy (SEM) and energy dispersive X-ray spectroscopy (EDS) measurements}

Morphological features of the powder samples were observed using a field emission gun scanning electron microscope (FEG-SEM), JEOL 5800 equipped with an EDS analyser. A thin layer of gold was evaporated on the samples in order to avoid charging when exposed to the electron beam. 


\subsection{Thermogravimetric analysis (TGA) and differential thermal analysis (DTA)}

Thermoanalytical measurements were conducted on powder samples using a SETARAM TAG 24 apparatus operating under inert atmospheric conditions. Samples were heated at a rate of $10{ }^{\circ} \mathrm{C} \min ^{-1}$ to a maximum temperature of $1400{ }^{\circ} \mathrm{C}$ and then cooled to room temperature. An alumina disc was used as a control. TGA/DTA curves were obtained by a computer at $4 \mathrm{~s}$ time intervals.

\subsection{Particle size distributions}

All particle size distributions were expressed as a mean with standard deviation for $n=$ 3 repeats.

\subsection{Fabrication of electroporcelain insulators}

The basic raw materials for the production of electroporcelain insulators are feldspar, kaolin and quartz. The raw materials used in this work were all sourced from deposits in Ghana. The two sources of the kaolin are specified in Section 2.1, while the feldspar and quartz were from deposits in Akyem-Akroso and Akwatia, respectively.

In formulating the insulators, only sieved raw materials with particle sizes below $355 \mu \mathrm{m}$ were used. Slurries of a number of different chemical compositions of the insulators were prepared by varying the proportions of the starting materials. A slip casting method was used to cast the slurry in a two part plaster of Paris mould. After $6 \mathrm{~h}$, the electroporcelain ceramics were de-moulded and left to dry in air overnight. These were then furnace heated at $6^{\circ} \mathrm{C} \min ^{-1}$ to $1200{ }^{\circ} \mathrm{C}$ and then sintered at this temperature for $2 \mathrm{~h}$, after which the furnace was switched off and the insulator left to cool overnight.

\subsection{Mechanical characterisation}

A modulus of rupture (MOR) test was used to determine the breaking strength of test bars as a proportion of starting materials. The test bars were made from the various electroporcelain chemical compositions examined by forcing plastic masses of the various compositions into moulds $20 \mathrm{~cm}$ long and $1 \mathrm{~cm}$ square in cross-section. After $6 \mathrm{~h}$, the green bodies were removed from the moulds and left to dry overnight. The firing schedule described above in Sect. 2.9 was used to produce bars for the MOR tests. These tests established the wt\% of the starting powders which produced insulators with the highest mechanical strength for the two sources of kaolin shown in Table 1. 


\section{Results and Discussion}

\subsection{Chemical, physical and thermal analyses}

Secondary electron scanning electron micrographs of the two clay powders are shown in Fig. 2. The Assin-Fosu kaolin has densely packed layers or sheets of aggregates, while the Kumasi kaolin has rather loosely held sheets of aggregates with some needles, suggesting that the two deposits are of different genesis. EDS spot analyses such as those shown in Fig. 2 indicated that the Assin-Fosu kaolin had a significantly higher ratio of aluminium to silicon concentration than the Kumasi kaolin.

Since chemical analysis from EDS spot analyses can only give a guide to the average chemical composition expected for the two clays, further, more detailed, analysis of the average chemical compositions of the clay powders was undertaken using X-ray fluorescence. These results are shown in Table 2. The trends seen in the Al and Si contents measured by EDS analysis for the two kaolins are confirmed by this more accurate chemical analysis. Although the flux content (taken to be the sum of their $\mathrm{Na}_{2} \mathrm{O}, \mathrm{K}_{2} \mathrm{O}, \mathrm{MgO}, \mathrm{CaO}$ and $\mathrm{SO}_{3}$ contents) is low in both samples, it is evident that the Assin-Fosu flux content is much lower than that for the Kumasi kaolin, principally because of the high level of $\mathrm{K}_{2} \mathrm{O}$ in the latter. As an aside, the relatively low content of $\mathrm{Fe}_{2} \mathrm{O}_{3}$ in the Assin-Fosu kaolin in comparison with the level of $\mathrm{Fe}_{2} \mathrm{O}_{3}$ in the Kumasi kaolin makes the Assin-Fosu kaolin more suitable for whitewares. The chemical composition data for the Assin-Fosu kaolin is similar to that reported in Table 3 by Efavi et al. (2012), but with a lower LOI, lower $\mathrm{Fe}_{2} \mathrm{O}_{3}$ and $\mathrm{K}_{2} \mathrm{O}$ contents and a higher $\mathrm{Na}_{2} \mathrm{O}$ content, reflecting a degree of statistical variability from sample to sample of this deposit of kaolin. However, significantly, the silica and alumina contents of this kaolin are similar in this study and the study of Efavi et al.

The results from the thermal analysis of the clay samples are shown in Figs. 3 and 4. As might be expected, the weight change profiles for the two kaolin samples from the TGA curves in Fig. 3 are broadly similar. Upon heating above $200{ }^{\circ} \mathrm{C}$, there is a gradual and continuous loss in weight up to around $420{ }^{\circ} \mathrm{C}$ in both samples, and then a more rapid change in the $420-600{ }^{\circ} \mathrm{C}$ temperature interval. This loss in weight up to $420{ }^{\circ} \mathrm{C}$ can be attributed to the loss of some hydroxylated water bound to the clay minerals and to other volatile materials (Carty and Senapati 1998). The weight change profile shown by the two kaolins in the temperature range of $420-600{ }^{\circ} \mathrm{C}$ is similar in form to that exhibited during the dehydroxylation of kaolinite leading to the formation of metakaolin $\left(\mathrm{Al}_{2} \mathrm{O}_{3} \cdot \mathrm{SiO}_{2}\right)(\mathrm{Carty}$ and 
Senapati 1998; Iqbal and Lee 1999; Ekosse 2000; Kirabira, Jonsson, and Byaruhanga 2011). Above $600^{\circ} \mathrm{C}$, almost all the impurities in the clays have volatised so that the TGA curves in Fig. 3 are in essence flat. However, there is a clear difference above $600^{\circ} \mathrm{C}$ between the two kaolin samples: while the percentage of mass lost by the Assin-Fosu kaolin in the $420-$ $600{ }^{\circ} \mathrm{C}$ temperature range is similar to that expected for pure kaolin samples (e.g., Fig. 13 of Carty and Senapati (1998)), the percentage of mass lost for the Kumasi kaolin is significantly lower than might be expected for a pure clay.

Interestingly, the two clay samples also show slightly different DTA signals upon heating (Fig. 4). The differences are most obvious in the temperature range $500-800{ }^{\circ} \mathrm{C}$ : the Kumasi kaolin shows a single endothermic peak centred at $500{ }^{\circ} \mathrm{C}$ while the Assin-Fosu kaolin shows two rather broad endothermic peaks centred at $600{ }^{\circ} \mathrm{C}$ and $800{ }^{\circ} \mathrm{C}$. The difference here can be attributed to the different mineralogical compositions of the two clay samples. One feature evident in the DTA signal of the Kumasi kaolin is the relatively weak exothermic signal at $1000{ }^{\circ} \mathrm{C}$ in comparison from the one arising from the Assin-Fosu kaolin. This exothermic peak arises from the formation of spinel as a consequence of the decomposition of metakaolin (e.g., Fig. 13 of Carty and Senapati, 1998). Otherwise, these DTA signals are similar to the ones reported in the literature on the thermal characteristics of kaolinite materials.

\subsection{XRD analysis and the mineralogy of the kaolin samples}

The XRD patterns of the two kaolin samples in the $2 \theta$ range $5-45^{\circ}$ are shown in Fig. 5. In neither case were any XRD reflections identified in the $2 \theta$ range $2-5^{\circ}$. It is evident that there are clear differences between the two kaolin samples. The Assin-Fosu kaolin XRD pattern has minority reflections attributable to mica (probably illite because of the small particle size), and, most probably, vermiculite, with the majority of reflections attributable to kaolinite. Quantifying the weight fractions using ICSD calculated data cards for kaolinite and illite suggested a weight fraction of kaolinite of $92 \pm 2 \mathrm{wt} \%$. The weight fraction of other clay minerals was $8 \pm 2 \mathrm{wt} \%$, of which $>90 \%$ was illite.

By comparison, it is evident in the Kumasi kaolin XRD pattern that there are strong reflections from quartz, together with reflections from kaolinite and minority reflections attributable to illite and paragonite. Quantifying the weight fractions using ICSD calculated data cards for these minerals suggested a weight fraction of kaolinite of $39 \pm 2 \mathrm{wt} \%$ and a weight fraction of quartz of $43 \pm 2 \mathrm{wt} \%$. The weight fraction of other clay minerals was $18 \pm$ 
$2 \mathrm{wt} \%$, of which $\sim 55 \%$ was illite. The presence of this high weight fraction of quartz in the Kumasi kaolin samples accounts for the relatively high level of silica in the chemical composition data in Table 2, the low weight loss on heating seen in Fig. 3 and the relatively weak exothermic peak in Fig. 4 from this kaolin. The XRD pattern from the Kumasi kaolin is similar to that of ball clay (e.g., Fig. 3 of Carty and Senapati, 1998): ball clays are kaolinitic plastic clays which can have significant levels of quartz and are characterised by wide ranges in chemical compositions (e.g., Baioumy and Ismael, 2014).

\subsection{Particle size analysis}

The average weight fractions from the sieve analysis are shown in Table 3. For each data set three different $400 \mathrm{~g}$ batches were analysed. It is evident that it was easier to break down the kaolin deposit from Kumasi than the one from Assin-Fosu; the presence of quartz in the Kumasi deposit helps in this context, and it is also consistent with this kaolin being a plastic clay.

\subsection{Electroporcelain insulators}

Electroporcelain insulators made from both Assin-Fosu and Kumasi kaolin deposits and fired at $1200{ }^{\circ} \mathrm{C}$ are shown in Fig. 6 using the procedures described in Sect. 2.9. While the insulator made from the Assin-Fosu kaolin has a whitish appearance, the one made from Kumasi kaolin has a brown tint. Although the wt $\%$ of feldspar used in making these insulators was different in the two cases, the level of $\mathrm{Fe}_{2} \mathrm{O}_{3}$ in the feldspar of $0.02 \mathrm{wt} \%$ was significantly less than the levels of $\mathrm{Fe}_{2} \mathrm{O}_{3}$ in the two sources of kaolin (Table 1). Therefore, the colour of the two fired insulators depended on the levels of $\mathrm{Fe}_{2} \mathrm{O}_{3}$ in the two deposits of kaolin, rather than on the level of $\mathrm{Fe}_{2} \mathrm{O}_{3}$ in the feldspar.

\subsection{Discussion}

The search for readily available local materials in Ghana for the fabrication of electroporcelain insulators has motivated the characterisation of these clay materials. The chemical composition, particle size and the amount of volatile material each play a significant role in the selection of clays for electroporcelain materials. From the results in Sections $3.1-$ 3.4 , it was evident that there was a noticeable variation in the chemical compositions and firing characteristics of the two clay materials. The difference here can be attributed to the ratio of $\mathrm{Al}_{2} \mathrm{O}_{3}$ to $\mathrm{SiO}_{2}$ in the two clay samples since Kumasi kaolin has a $\mathrm{Al}_{2} \mathrm{O}_{3}: \mathrm{SiO}_{2}$ wt.\% 
ratio of $0.38: 1$ in comparison with that of $0.71: 1$ for Assin-Fosu kaolin. These differences can be attributed to the different geological conditions existing during the formation of the clay minerals. In particular, the Kumasi kaolin has a significant weight fraction of fine particulate matter, consistent with it being a plastic clay deposit. The relative purity of the Assin-Fosu kaolin and the low level of iron present make it much more suitable for the fabrication of electroporcelain ceramics and whitewares in comparison with the Kumasi kaolin. Instead, the high siliceous content of the Kumasi kaolin makes it more suitable for the production of wall and floor tiles where the chemical compositions of the starting materials can withstand large variations in chemical composition without significant degradation to the mechanical and electrical performance of the final product, and where colour is not a significant factor.

\section{Conclusions}

In this work two types of Ghanaian kaolin have been evaluated for their potential for electroporcelain fabrication. On the basis of our analyses, the conclusion has been drawn that Assin-Fosu kaolin is much more suitable than Kumasi kaolin for electroporcelain fabrication. We suggest that Assin-Fosu kaolin, Akyem-Akroso feldspar and Akwatia quartz could all be used as locally sourced raw materials to start electroporcelain fabrication in Ghana for the expansion of the national electricity transmission network within the country.

\section{Acknowledgements}

Part of this work was undertaken at the Department of Materials Science and Metallurgy at the University of Cambridge under the Cambridge-Africa Fellowship programme, for which AY and KMK acknowledge the Cambridge African Partnership for Research Exchange (CAPREx) for funding this study. AY and EKT also acknowledge support from the Office of Research, Innovation and Development (ORID), University of Ghana, Grant \#URF/7/029/2013-2014. Furthermore, we are grateful to Andrew Moss and the late Graham Sharp for their technical assistance and also Michael Misson, the CEO of Almath Crucibles Company Limited, Cambridge, U.K. for useful discussions and Prof. Benjamin Kankpenyeng, University of Ghana, for the geographical map used in this paper. 


\section{References}

Agyei-Tuffour, B., Bensah, Y.D., Damoah, L.N.W., Dodoo-Arhin, D., Yaya, A., Nyankson, E., Annan, E., Sarkodee, E., Efavi, J.K., 2014. Synthesis and microstructural characterization of kaolin-polyethylene composites. Polymer Composites 35, 15071515.

Baioumy, H.M., Ismael, I.S., 2014. Composition, origin and industrial suitability of the Aswan ball clays, Eqypt. Appl. Clay Sci., 102, 202.

Bertolino, S., Lagaly, G., 2003. Clay Minerals and the Environment. Appl. Clay Sci., 24 1-2.

Brindley, G.W., Nakahira, M., 1959. The kaolinite-mullite seaction series: I, a survey of outstanding problems. J. Am. Ceram. Soc. 42, 311-14.

Brindley, G.W., Brown, G. (eds.), 1980. Crystal Structures of Clay Minerals and their X-ray Identification. The Mineralogical Society, London (495 pp).

Carty, W.M., Senapati, U., 1998. Porcelain-raw materials, processing, phase evolution, and mechanical behavior. J. Am. Ceram. Soc. 81, 3-20.

Cases, J.M., Cunin, P., Grillet, Y., Poinsignon, C., Yvon, J., 1986. Methods of analysing morphology of kaolinites: relations between crystallographic and morphological properties. Clay Miner. 21, 55-68.

Choudhary, R.N.P., Patri, S.K., 2009. Dielectric Materials: Introduction, Research and Applications. Nova Science Publishers, Hauppauge, N.Y. (152 pp.).

Cravero, F., Gonzalez, I., Galan, E., Dominguez, E., 1997. Geology, mineralogy, origin and possible applications of some Argentinian kaolins in the Neuquen basin. Appl. Clay Sci. 12, 27-42.

Dodoo-Arhin, D., Konadu, D.S., Annan, E., Buabeng, F.P., Yaya, A., Agyei-Tuffour, B., 2013. Fabrication and characterisation of Ghanaian bauxite red mud-clay composite bricks for construction applications. Am. J. Mater. Sci. 3, 110-119.

Efavi, J.K., Damoah, L., Bensah, D.Y., Dodoo Arhin, D., Tetteh, D., 2012. Development of porous ceramic bodies from kaolin deposits for industrial applications. Appl. Clay Sci. 65-66, 31-36.

Ekosse, G., 2000. The Makoro kaolin deposit, southeastern Botswana: its genesis and possible industrial applications. Appl. Clay Sci. 16, 301-320.

Goody, J., 1972. The Myth of the Bagre. Oxford Library of African Literature, Clarendon Press, Oxford (381 pp.).

Iqbal, Y., Lee, W.E., 1999. Fired porcelain microstructures revisited. J. Am. Ceram. Soc. 82, 3584-3590.

Kirabira, J.B., Jonsson, S., Byaruhanga, J.K., 2011. Beneficiation and evaluation of Mutaka kaolin. Proceedings of the Second International Conference on Advances in Engineering and Technology (AET2011), Makerere University, Entebbe, Uganda, Macmillan Uganda, pp. 169-175. 
Kurihara, H., Kitagawa, Y., Nagatsuka. S., 2003. Clay-mineralogical characteristics of soils distributed under warm-temperate forest climate in Nyu mountains, Fukui Prefecture, Central Japan. Soil Sci. Plant Nutr. 49, 405-15.

López-Galindo, A., Viseras, C., Cerezo, P., 2007. Compositional, technical and safety specifications of clays to be used as pharmaceutical and cosmetic products. Appl. Clay Sci. 36, 51-63.

Murray, H.H., Bundy, W.M., Harvey, C.C. (eds.), 1993. Kaolin Genesis and Utilization (a collection of papers presented at the Keller '90 kaolin symposium). The Clay Minerals Society, Boulder, Colorado (341 pp.).

Murray, H.H., 2000. Traditional and new applications for kaolin, smectite, and palygorskite: a general overview. Appl. Clay Sci. 17, 207-221.

Nkoumbou, C., Njoya, A., Njoya, D., Grosbois, C., Njopwouo, D., Yvon, J., Martin, F., 2009. Kaolin from Mayouom (Western Cameroon): Industrial suitability evaluation. Appl. Clay Sci. 43, 118-24.

Olupot, P.W., Jonsson, S., Byaruhanga, J.K., 2010. Development and characterisation of triaxial electrical porcelains from Ugandan ceramic minerals. Ceram. Inter. 36, 14551461.

Olupot, P.W., Jonsson, S., Byaruhanga, J.K., 2013. Effects of the sintering process on properties of triaxial electrical porcelain from Ugandan ceramic minerals. Int. J. Chem., Molec., Nucl., Mater. Metall. Engng. 7, 267-273.

Pinheiro, P.G., Fabris, J.D., Mussel, W.N., Murad, E., Scorzelli, R.B., Garg, V.K., 2005. Beneficiation of a commercial kaolin from Mar de Espanha, Minas Gerais, Brazil: Chemistry and mineralogy. J. South Am. Earth Sci. 20. 267-71.

Saikia, N. J., Bharali, D.J., Sengupta, P., Bordoloi, D., Goswamee, R.L., Saikia, P.C., Borthakur, P.C., 2003. Characterization, beneficiation and utilization of a kaolinite clay from Assam, India. Appl. Clay Sci., 24, 93-103.

Siddiqui, M.A., Ahmed, Z., Saleemi, A.A., 2005. Evaluation of Swat kaolin deposits of Pakistan for industrial uses. Appl. Clay Sci. 29, 55-72.

Stathis, G., Ekonomakou, A., Stournaras, C.J., Ftikos, C., 2004. Effect of firing conditions, filler grain size and quartz content on bending strength and physical properties of sanitaryware porcelain. J. Eur. Ceram. Soc. 24, 2357-66.

Velde, B., 1992. Introduction to Clay Minerals: Chemistry, Origins, Uses and Enviromental Significance. Chapman and Hall, London (198 pp.).

Yaya, A., Agyei-Tuffour, B., Dodoo-Arhin, D., Nyankson, E., Annan, E., Konadu, D.S., Sinayobye, E., Baryeh, E.A., Ewels, C.P., 2012. Layered nanomaterials - a review. Global J. Engng. Design Technol. 2, 32-41. 


\section{Figure Captions}

Fig. 1. Regional map of Ghana showing locations of the Assin-Fosu and Kumasi kaolin deposits. Two small yellow dots show the exact locations of these deposits on the left-hand enlargement of the south-west corner of Ghana.

Fig. 2. (a), (b) SEM images of the Assin-Fosu kaolin and Kumasi kaolin, respectively. (c), (d) examples of EDS spot analyses of (c) Assin-Fosu and (d) Kumasi kaolin, consistent with the Assin-Fosu kaolin having a higher Al:Si ratio than the Kumasi kaolin.

Fig. 3. Mass change on heating of the two clay powder samples.

Fig. 4. DTA signals of heat flow on heating of samples. For clarity, the curve for the Kumasi kaolin has been displaced by $+30 \mu \mathrm{V}$ on the vertical axis relative to the curve in blue for the Assin-Fosu kaolin.

Fig. 5. XRD patterns for the different kaolin deposits: the pattern for the Assin-Fosu kaolin is shown in blue, and the pattern for the Kumasi kaolin is shown in red. Reflections from mica (in the form of illite) and vermiculite are labelled ' $m$ ' and ' $v$ ' respectively on the XRD pattern of the Assin-Fosu kaolin. Reflections from the two mica group minerals illite and paragonite are labelled ' $\mathrm{m}$ *' and reflections from quartz are labelled 'q' on the XRD pattern of the Kumasi kaolin.

Fig. 6. Fired electroporcelain insulators at $1200{ }^{\circ} \mathrm{C}$ made from; (a) Assin-Fosu kaolin and (b) Kumasi kaolin. The scale bar is $5 \mathrm{~cm}$. 
Table 1. Optimum chemical compositions of fabricated electroporcelain insulators in wt.\%

\begin{tabular}{lcc}
\hline Kaolin starting material: & Assin-Fosu (wt. \%) & Kumasi (wt. \%) \\
\cline { 1 - 2 } Material & & \\
\hline Kaolin & 42.1 & 37.2 \\
Feldspar & 21.8 & 24.6 \\
Quartz & 36.1 & 38.2 \\
\hline
\end{tabular}

Table 2. Chemical compositions from X-ray fluorescence (in wt.\%).

\begin{tabular}{lcc}
\hline Oxide & Assin-Fosu kaolin & Kumasi kaolin \\
\hline $\mathrm{Na}_{2} \mathrm{O}$ & $2.14 \pm 0.11$ & $1.37 \pm 0.03$ \\
$\mathrm{MgO}$ & $1.14 \pm 0.08$ & $0.79 \pm 0.05$ \\
$\mathrm{Al}_{2} \mathrm{O}_{3}$ & $35.17 \pm 2.1$ & $22.19 \pm 2.1$ \\
$\mathrm{SiO}_{2}$ & $49.79 \pm 2.7$ & $58.59 \pm 3.2$ \\
$\mathrm{P}_{2} \mathrm{O}_{5}$ & $0.03 \pm 0.004$ & $0.04 \pm 0.005$ \\
$\mathrm{SO}_{3}$ & $0.04 \pm 0.002$ & $0.01 \pm 0.0005$ \\
$\mathrm{Cl}$ & $0.13 \pm 0.001$ & $0.13 \pm 0.002$ \\
$\mathrm{~K}_{2} \mathrm{O}$ & $0.60 \pm 0.009$ & $4.20 \pm 0.009$ \\
$\mathrm{CaO}$ & $0.20 \pm 0.007$ & $0.12 \pm 0.005$ \\
$\mathrm{TiO}_{2}$ & $0.14 \pm 0.002$ & $0.34 \pm 0.001$ \\
$\mathrm{MnO}$ & $0.04 \pm 0.008$ & $0.19 \pm 0.006$ \\
$\mathrm{Fe}_{2} \mathrm{O}_{3}$ & $0.76 \pm 0.005$ & $1.99 \pm 0.008$ \\
$\mathrm{LosS}$ on ignition & $9.6 \pm 0.007$ & $10.08 \pm 0.003$ \\
\hline
\end{tabular}

Table 3. Average weight fractions of the two milled kaolins as a function of sieve size for $400 \mathrm{~g}$ batches ground for $11 \mathrm{hr}$ in a cascading ball mill using alumina balls.

\begin{tabular}{|c|c|c|}
\hline Kaolin & Assin-Fosu & Kumasi \\
\hline \multicolumn{3}{|l|}{ Analyses } \\
\hline Fraction $>630 \mu \mathrm{m}$ & $9.9 \pm 0.6$ & $0.04 \pm 0.01$ \\
\hline Fraction $500-630 \mu \mathrm{m}$ & $6.5 \pm 0.1$ & $0.12 \pm 0.1$ \\
\hline Fraction $355-500 \mu \mathrm{m}$ & $10.8 \pm 0.4$ & $12.3 \pm 0.7$ \\
\hline Fraction $90-355 \mu \mathrm{m}$ & $62.8 \pm 0.4$ & $82.5 \pm 1.2$ \\
\hline Fraction $63-90 \mu \mathrm{m}$ & $4.1 \pm 0.2$ & $1.3 \pm 0.1$ \\
\hline Fraction $<63 \mu \mathrm{m}$ & $5.2 \pm 0.4$ & $3.8 \pm 0.6$ \\
\hline
\end{tabular}




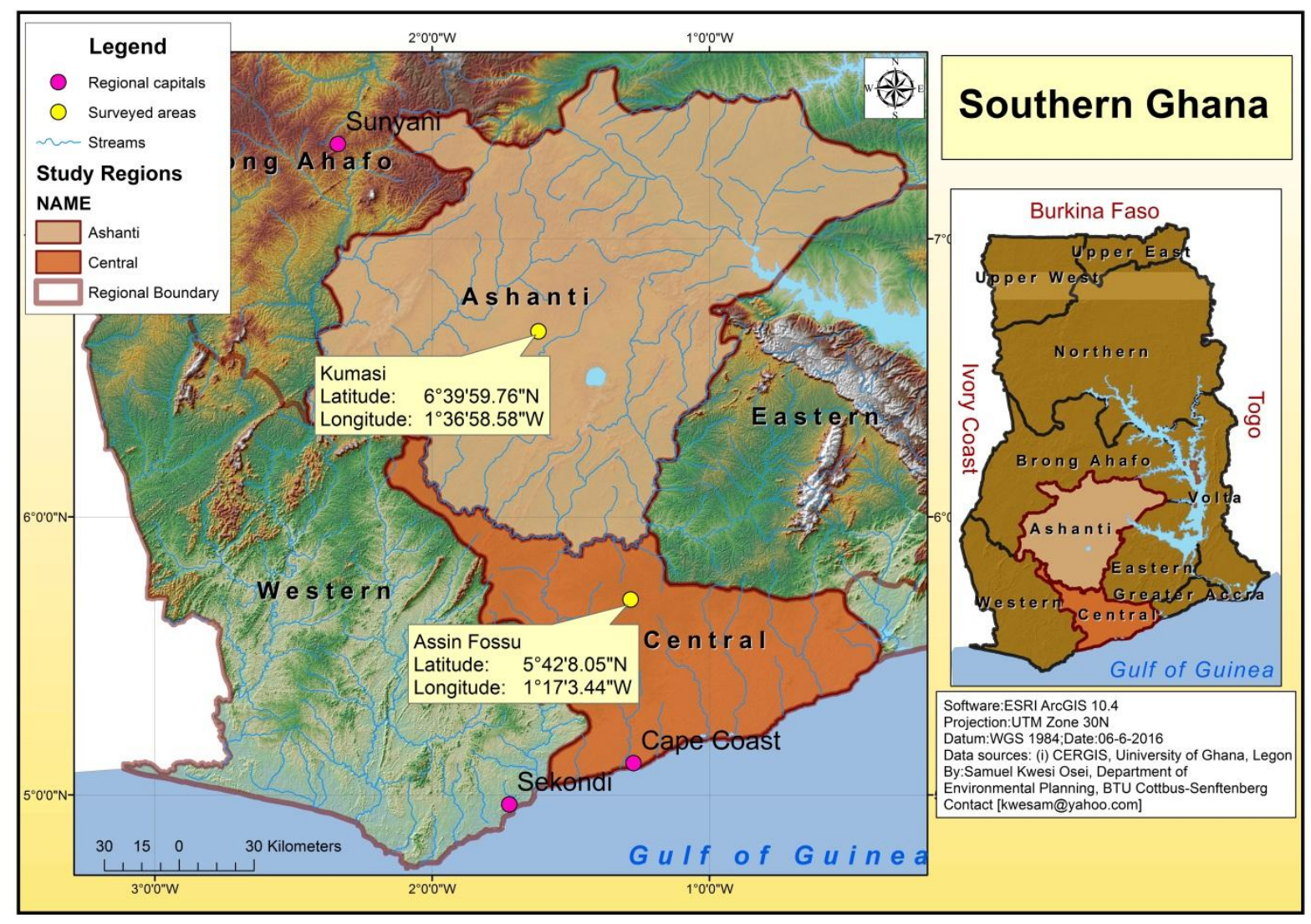

Fig. 1. Regional map of Ghana showing locations of the Assin-Fosu and Kumasi kaolin deposits. Two small yellow dots show the exact locations of these deposits on the left-hand enlargement of the south-west corner of Ghana. 


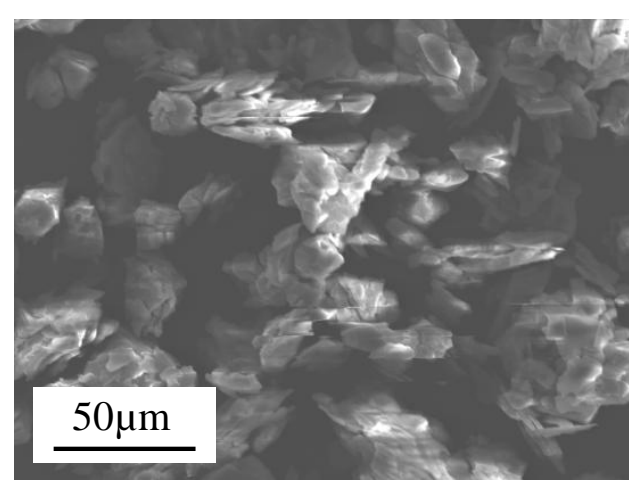

(a)

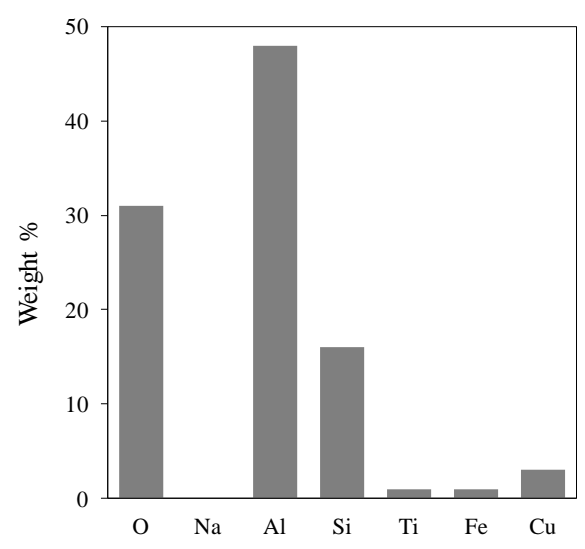

(c)

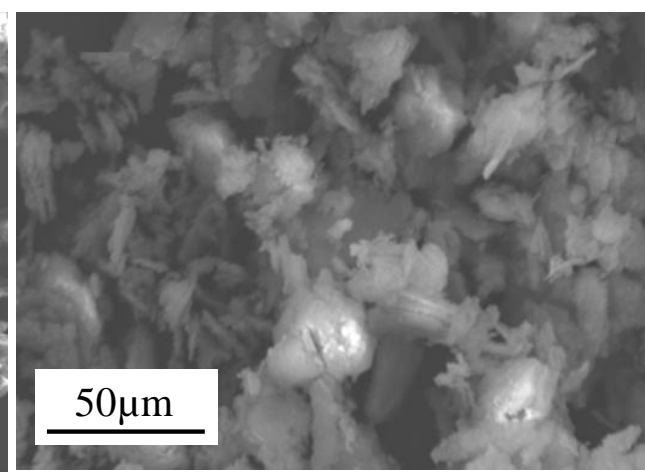

(b)

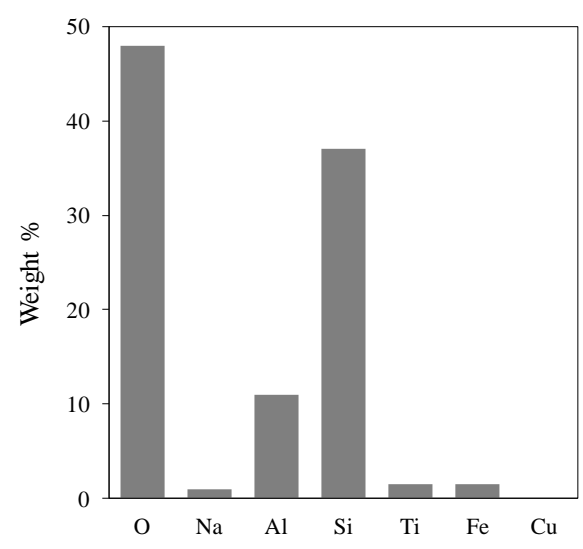

(d)

Fig. 2. (a), (b) SEM images of the Assin-Fosu kaolin and Kumasi kaolin, respectively. (c), (d) examples of EDS spot analyses of (c) Assin-Fosu and (d) Kumasi kaolin, consistent with the Assin-Fosu kaolin having a higher Al:Si ratio than the Kumasi kaolin. 


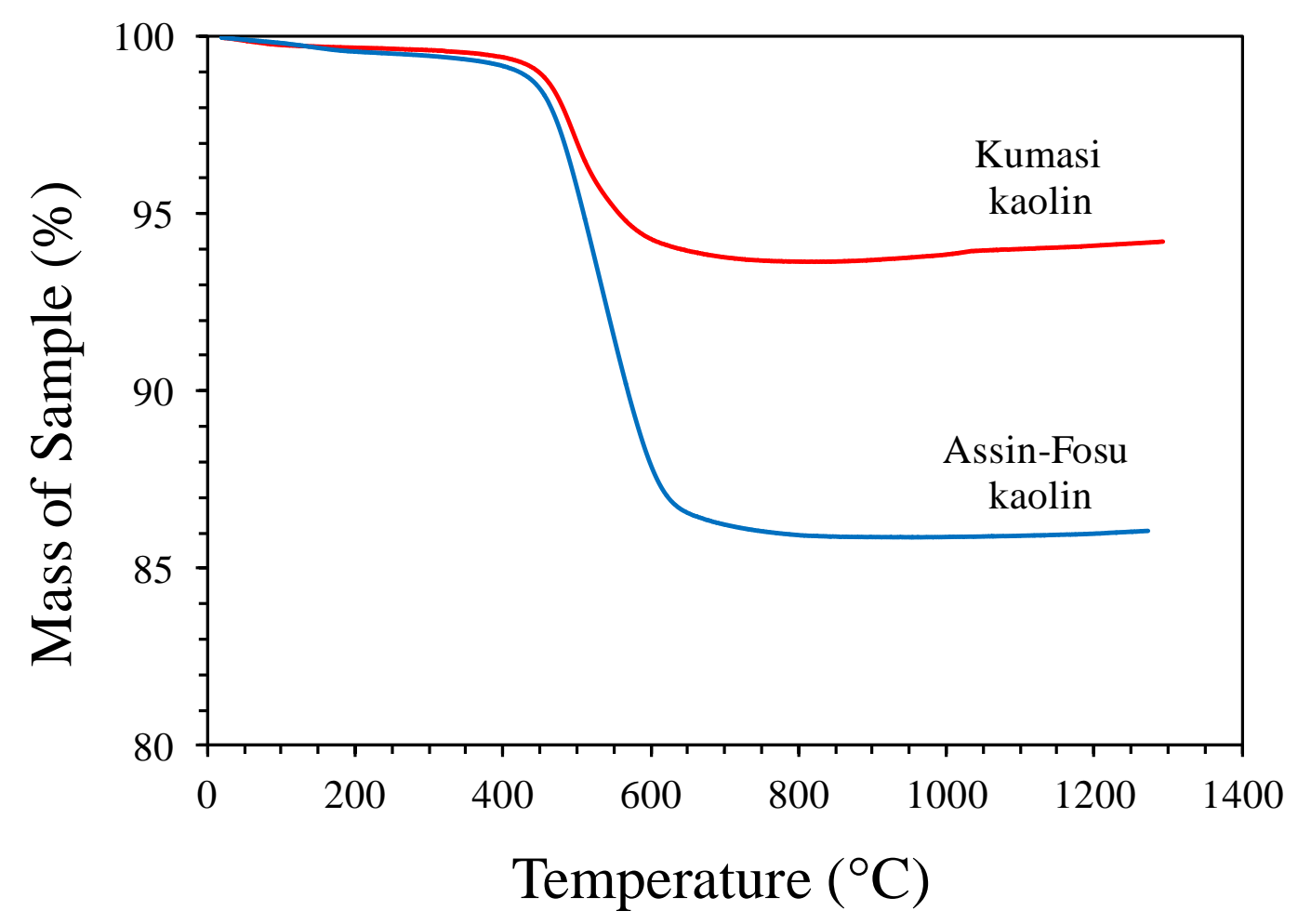

Fig. 3. Mass change on heating of the two clay powder samples. 


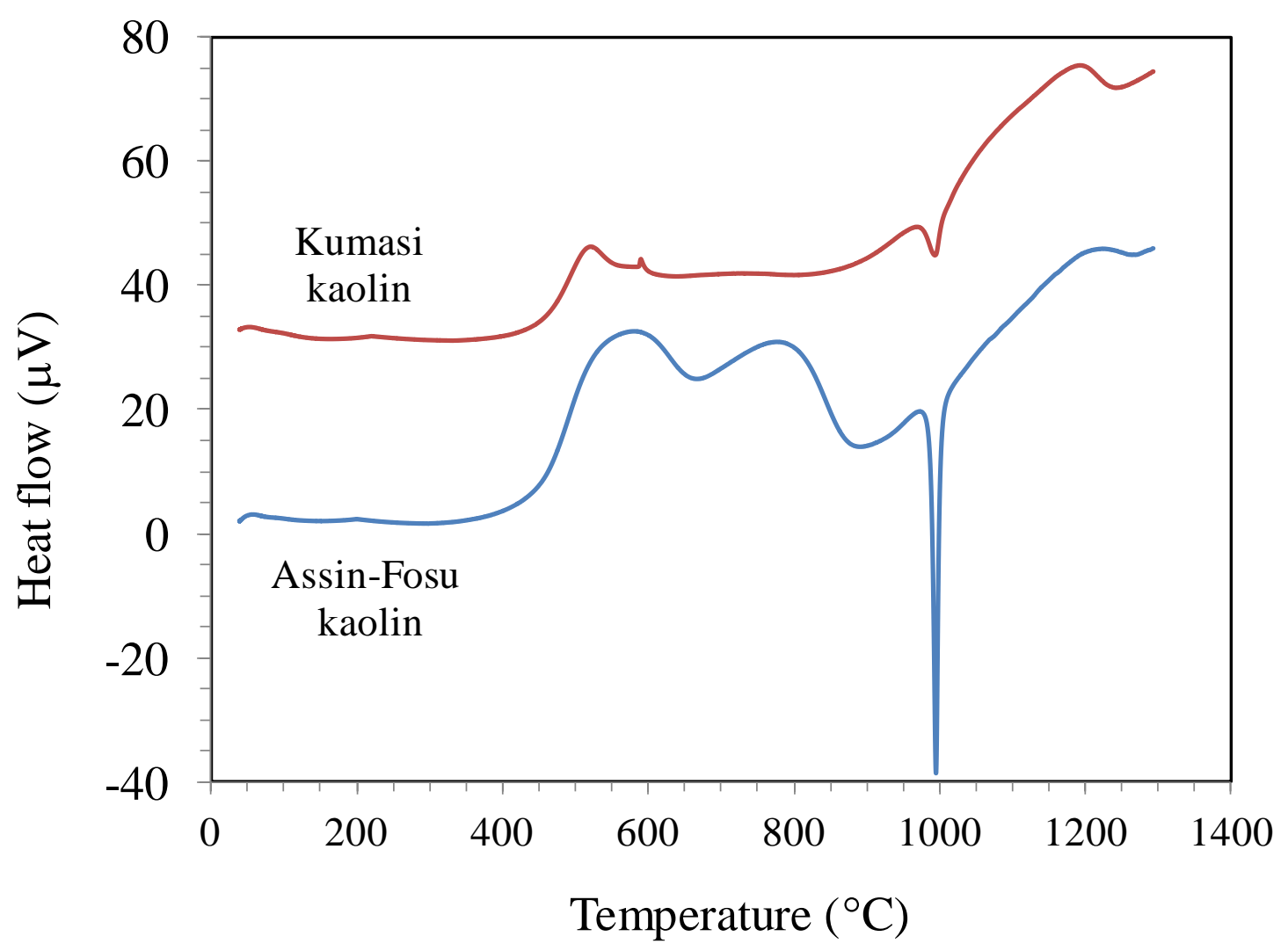

Fig. 4. DTA signals of heat flow on heating of samples. For clarity, the curve for the Kumasi kaolin has been displaced by $+30 \mu \mathrm{V}$ on the vertical axis relative to the curve in blue for the Assin-Fosu kaolin. 


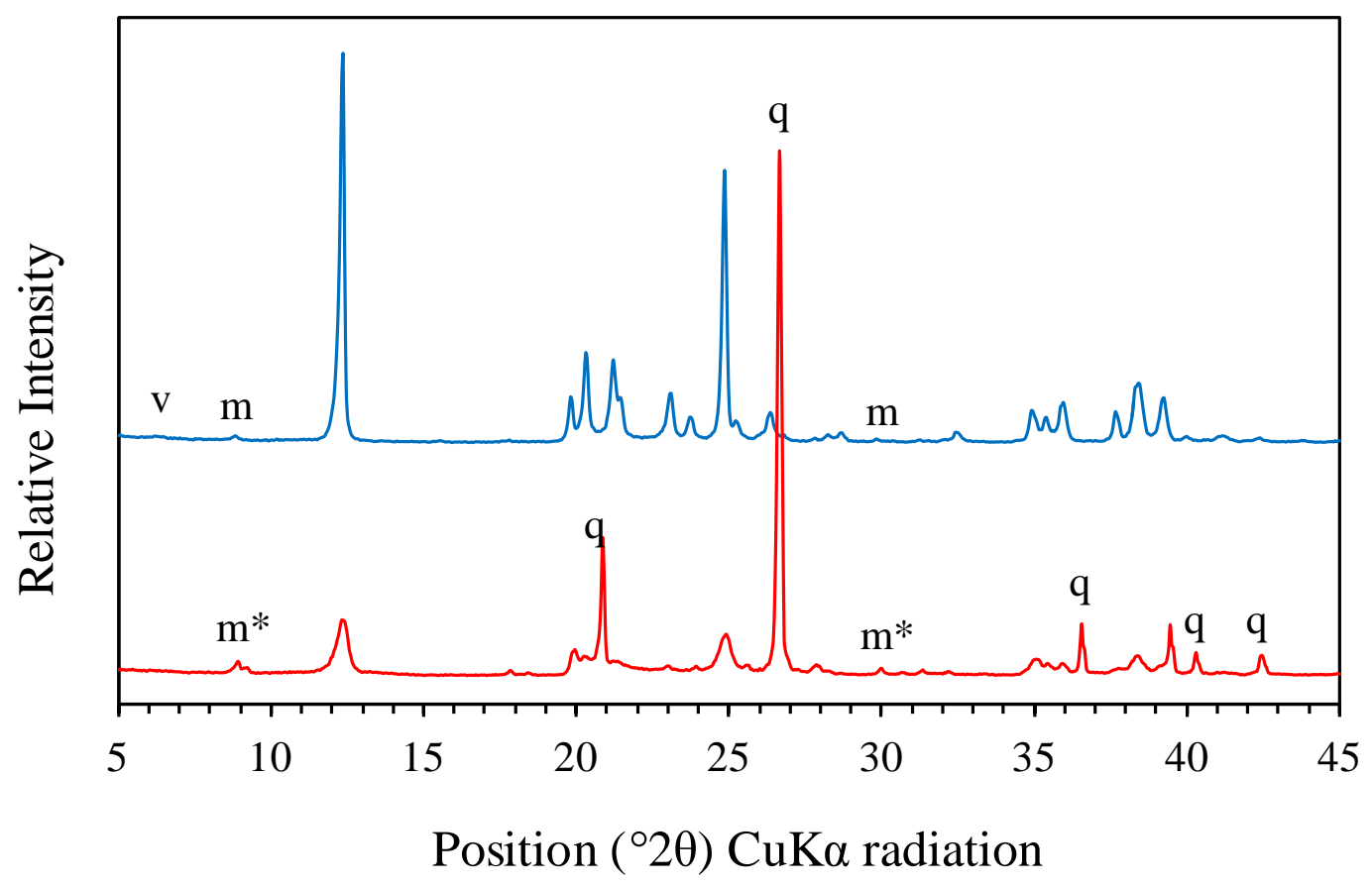

Fig. 5. XRD patterns for the different kaolin deposits: the pattern for the Assin-Fosu kaolin is shown in blue, and the pattern for the Kumasi kaolin is shown in red. Reflections from mica (in the form of illite) and vermiculite are labelled ' $m$ ' and ' $v$ ' respectively on the XRD pattern of the Assin-Fosu kaolin. Reflections from the two mica group minerals illite and paragonite are labelled ' $\mathrm{m}$ *' and reflections from quartz are labelled 'q' on the XRD pattern of the Kumasi kaolin. 


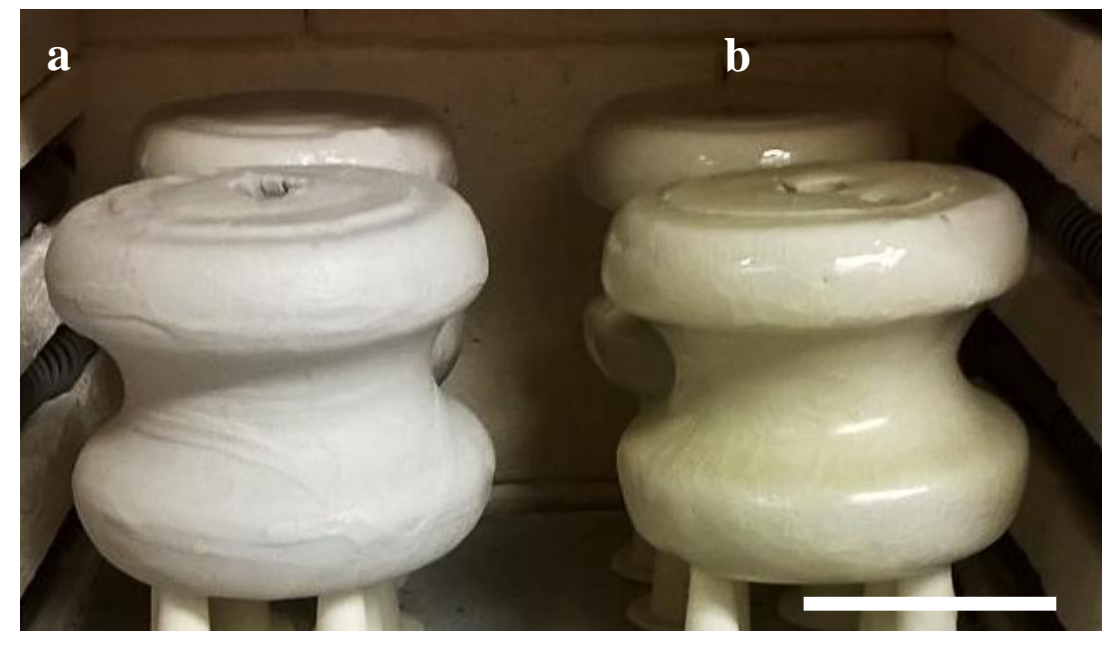

Fig. 6. Fired electroporcelain insulators at $1200{ }^{\circ} \mathrm{C}$ made from; (a) Assin-Fosu kaolin and (b) Kumasi kaolin. The scale bar is $5 \mathrm{~cm}$. 